\title{
Occurrence of the Phoronid Phoronopsis albomaculata in Cocos Island, Costa Rica ${ }^{1}$
}

\author{
Harlan K. Dean, ${ }^{2}$ Jeffrey A. Sibaja-Cordero, ${ }^{3,4,6}$ and Forge Cortés 3,5
}

\begin{abstract}
The phoronid Phoronopsis albomaculata was collected in subtidal (28$35 \mathrm{~m}$ ) sandy sediments in Bahía Chatham during a benthic survey designed to describe the biota of Cocos Island (Isla del Coco), Costa Rica, a national park and Human Heritage Site. Occurrence of this widespread species in Cocos Island is the first report of a phoronid for Costa Rican waters and is the second locality recorded for the eastern Pacific. Taxonomically significant characters (presence of an epidermal collar, extent of coiling of lophophore and nephridia) are discussed. Comparisons are made between depth and abundance of this species from Cocos Island and results of previous studies.
\end{abstract}

THE PHORONIDS are a small group of lophophorate marine invertebrates given phylumlevel status by some although others regard them, along with the Brachiopoda and Bryozoa, as a class within the phylum Lophophorata (Emig 1979, 2009). Regardless of their higher-level classification, the phoronids are subdivided into two genera, Phoronis and Phoronopsis, with only 10 species described worldwide. These vermiform benthic organisms are tube-dwelling suspension feeders

\footnotetext{
${ }^{1}$ This paper is part of the Centro de Investigación en Ciencias del Mar y Limnología-Universidad de Costa Rica (CIMAR-UCR) project "Conocimiento y gestión de medios marinos y coralinos del Área de Conservación Marina Isla del Coco," No. 808-A7-520 of Fundación de la Universidad de Costa Rica para la Investigación (FUNDEVI-UCR), and was funded by the French Fund for the World Environment (FFEM). Manuscript accepted 14 September 2009.

${ }^{2}$ Department of Invertebrates, Museum of Comparative Zoology, Harvard University, 26 Oxford Street, Cambridge, Massachusetts 02138.

${ }^{3}$ Centro de Investigación en Ciencias del Mar y Limnología (CIMAR), Universidad de Costa Rica, San Pedro, 11501-2060 San José, Costa Rica.

${ }^{4}$ Programa de Doctorado del Departamento de Ecología y Biología Animal, Facultad de Ciencias del Mar, Universidad de Vigo, Spain.

${ }^{5}$ Escuela de Biología, Universidad de Costa Rica.

${ }^{6}$ Corresponding author (e-mail: jeffro.alejandro@ gmail.com).
}

Pacific Science (2010), vol. 64, no. 3:459-462

doi: $10.2984 / 64.3 .459$

(C) 2010 by University of Hawai'i Press

All rights reserved with a U-shaped digestive tract and a tentacled lophophore. Food particles such as phytoplankton and detritus are captured on the ciliated tentacles of the lophophore and transported to the mouth at the base of the lophophore. The anus is found dorsal to the mouth outside the lophophore at the tip of an anal papilla that usually also bears a pair of nephridial openings.

Emig (1971, 1979, 1982a) reviewed the 10 known species of Phoronida and later (Emig 2009) reviewed the five species known to occur along the Pacific and Caribbean coasts of Central America. At the time of the latest review (Emig 2009) no phoronids had been reported from Costa Rican waters although it is likely that several species do occur but have not yet been reported due to low sampling effort. Recently, as part of a long-term effort to describe the biota of Cocos Island by the Centro de Investigación en Ciencias del Mar y Limnología (CIMAR) of the Universidad de Costa Rica, specimens of Phoronopsis albomaculata Gilchrist, 1907, have been obtained and are discussed here.

\section{MATERIALS AND METHODS}

Benthic infaunal collection was carried out during the CIMAR-COCO-I (9-20 October 2007) and CIMAR-COCO-II (2-13 April 2008) expeditions to Isla del Coco (Cocos Island), Pacific Costa Rica, 5 $30^{\prime} 57^{\prime \prime} \mathrm{N}, 87^{\circ}$ 03' 40" W (Cortés 2008). The main objective was to study the diversity of marine organ- 


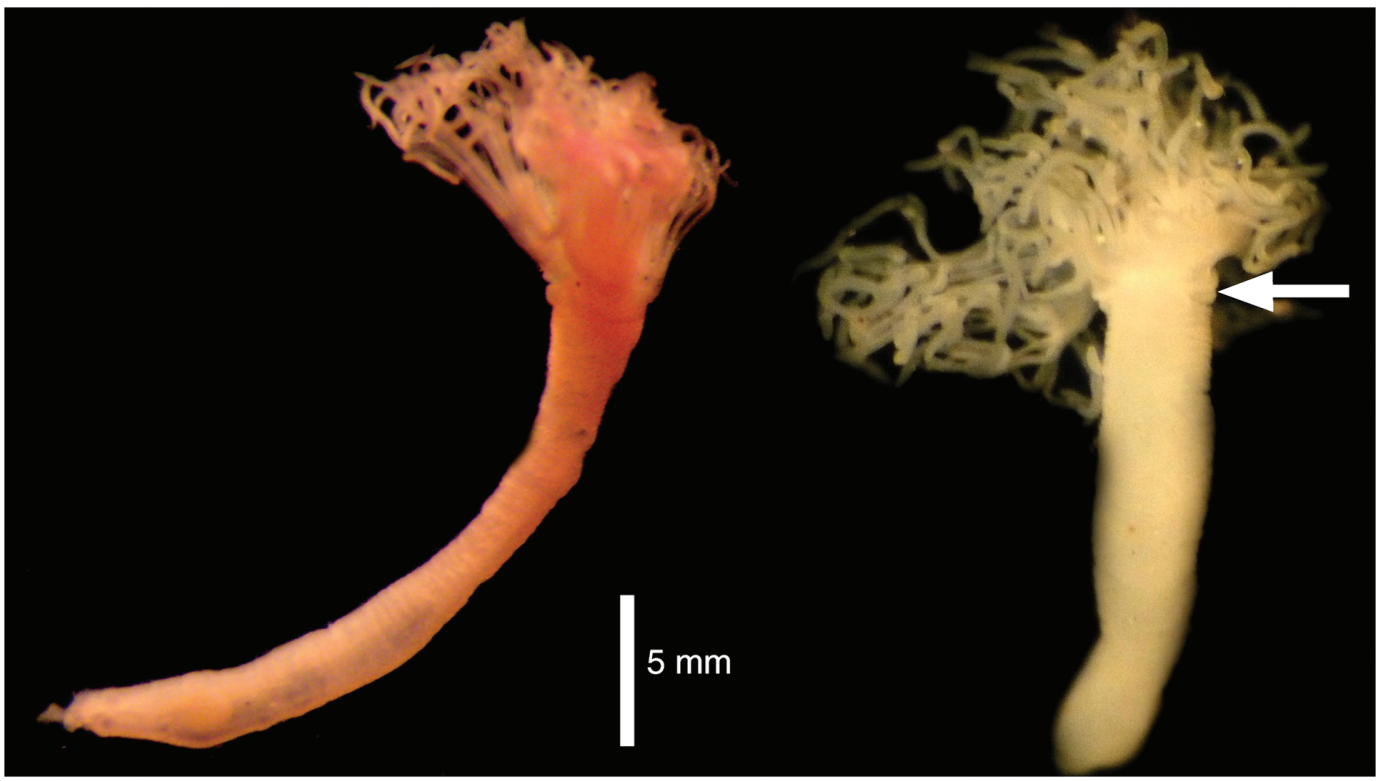

Figure 1. Costa Rican specimens of Phoronopsis albomaculata Gilchrist, 1907, Bahía Chatham, Cocos Island, Costa Rica, collected in October 2007 (stained with Rose Bengal). Arrow indicates epidermal collar fold.

isms at this national park and Human Heritage Site. A total of 14 Petite Ponar grab (sampling area: 152 by $152 \mathrm{~mm}$ ) samples were collected following a depth gradient (5 to $76 \mathrm{~m}$ ) in the subtidal sandy bottom of Bahía Chatham, and 11 sediment samples were collected by hand in plastic sealable bags during scuba dives at seven localities (7 to $29 \mathrm{~m}$ ) on the north side of the island. Organisms were preserved with formalin diluted to $5 \%$ in seawater and stained with Rose Bengal. The samples were sieved through a $500 \mu \mathrm{m}$ mesh (Vargas 1987) and stored in glass vials filled with $70 \%$ ethanol.

\section{RESULTS AND DISCUSSION}

The genus Phoronopsis is most easily differentiated from the genus Phoronis by its possession of an epidermal collar fold below the lophophore (Emig 1971, 1979), and this fold is evident in the Costa Rican specimens (Figure 1). Emig (2009) reported two species within the genus Phoronopsis as known to occur in the Pacific coast of Central America, P. albomaculata and P. harmeri Pixell, 1912.
These two species may be differentiated most easily by their lophophore: that of $P$. albomaculata is only slightly coiled whereas that of $P$. harmeri is spirally coiled for $1 \frac{1}{2}$ to 2 turns. The lophophores of both of the Costa Rican specimens are only slightly coiled, similar to the type II coils illustrated in Emig (1979). In addition, the nephridia are elongate but rounded with a central funnel (Figure 2) similar to that pictured by Emig (1979: fig. $4 C$ iii) for $P$. albomaculata. It did not resemble the nephridia of $P$. harmeri shown in Emig (1979: fig. $4 E$ ii).

Emig (2009) reported that P. albomaculata is considered a cosmopolitan species, first described from False Bay, South Africa, and since been collected from Panama, the Ivory Coast, Madagascar, Hawai'i, and Australia (Emig 1982b, Emig and Golikov 1990, Emig and Roldán 1992, Bailey-Brock and Emig 2000). The occurrence of this widespread species on Cocos Island, Costa Rica, is not surprising, but it is important to note because the prior record from Pacific Panama (Emig $1982 b$ ) had been the only record from the eastern Pacific. 


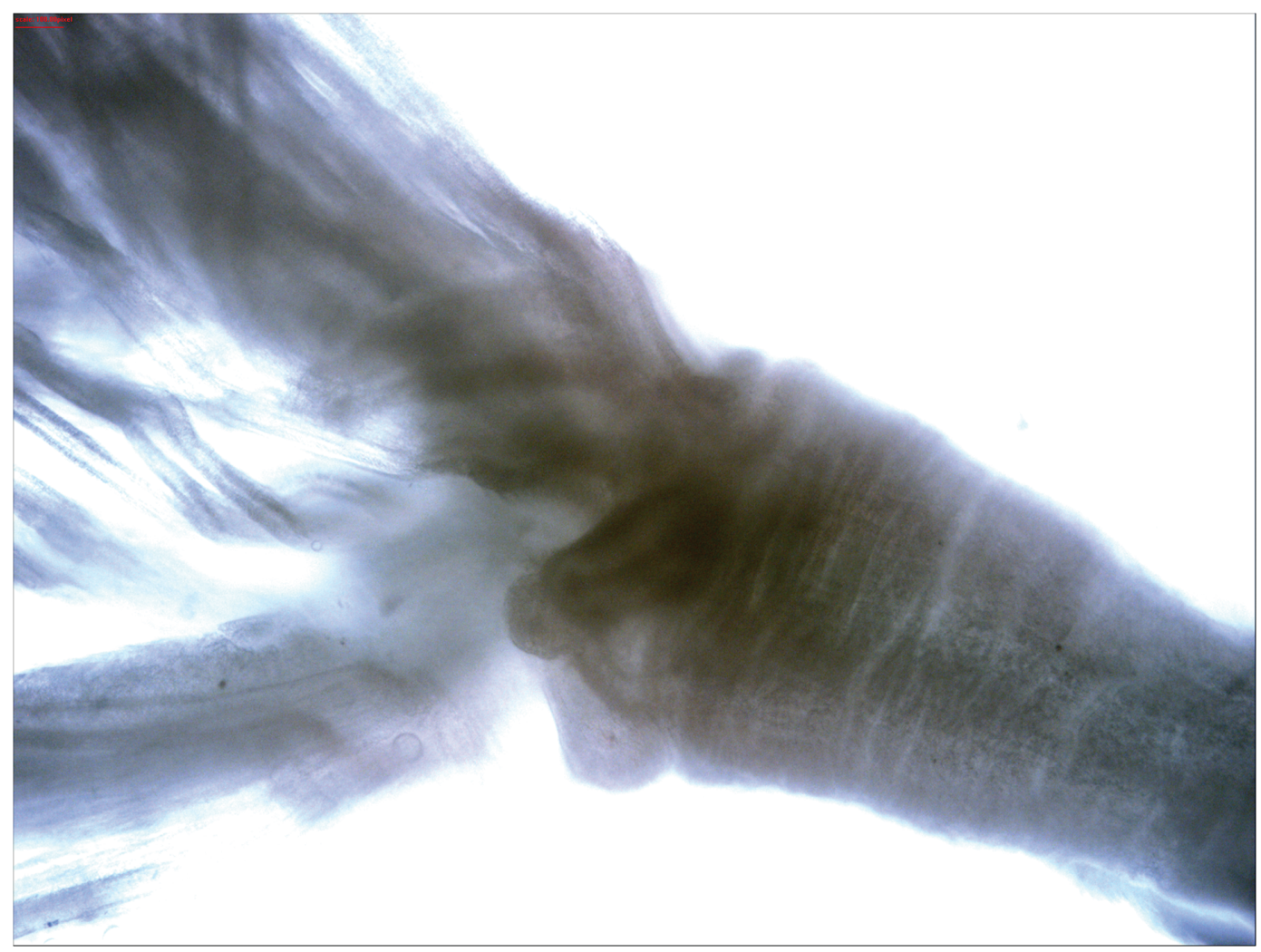

Figure 2. Costa Rican specimen of Phoronopsis albomaculata Gilchrist, 1907, showing the left nephridium, ventral view. Specimen was cleared in glycerol and viewed at $40 \times$.

Emig (2009) reported that $P$. albomaculata was known from 1 to $55 \mathrm{~m}$ in muddy to sandy bottom sediments. Its distribution seems to relate mainly to coarser-grained sands with moderate levels of organic matter (Emig $1982 a$ ). The two specimens of this species were collected from Cocos Island only during the October 2007 expedition and were found in 28 and $35 \mathrm{~m}$ depth, respectively, both on sandy sediments.

Phoronids are generally thought of as being low in abundance and only a minor component of bethic samples, but this may not always be the case. On the Algerian coast of the Mediterranean Sea, Bakalem et al. (2009) reported that in several stations the species Phoronis psammophila Cori, 1889, composed over $10 \%$ of the benthos, and Niermann et al. (1990) found that a species of the genus
Phoronis was highly variable in abundance in samples from the German Bight, making up between $1 \%$ and $75 \%$ of community abundance. Emig and Bailey-Brock (1987) and Bailey-Brock and Emig (2000) reported two species of Phoronis (P. ovalis and P. hippocrepia) at densities of up to thousands of individuals per square meter in Hawai'i. Both burrow in coralline rock and carbonate materials and have great potential for asexual reproduction by transverse fission.

Only two specimens of Phoronopsis albomaculata were collected at Cocos Island, each in a single grab sample. None was encountered in samples taken while using scuba in the same area. The sandy sediments on Cocos were dominated by polychaetes and crustaceans, and $P$. albomaculata was a relatively insignificant component. Thomassin and Emig 
(1983) cited densities of $P$. albomaculata of 70 or fewer individuals per square meter in Mozambique, and Emig (2007) found P. albomaculata at several stations with densities under nine individuals per square meter in a lagoon in New Caledonia. Based on those previous studies, the low density of $P$. albomaculata on Cocos Island is not unexpected.

\section{ACKNOWLEDGMENTS}

Fieldwork for this study was carried out with the help of E. Ruiz and the staff of the MV Phoenix and MY Adventure. O. Lizano lent us the Petite Ponar grab.

\section{Literature Cited}

Bailey-Brock, J. H., and C. C. Emig. 2000. Hawaiian Phoronida (Lophophorata) and their distribution in the Pacific region. Pac. Sci. 54:119-126.

Bakalem, A., T. Ruellet, and J. C. Dauvin. 2009. Benthic indices and ecological quality of shallow Algeria fine sand community. Ecol. Indicat. 9:395-408.

Cortés, J. 2008. Historia de la investigación marina de la Isla del Coco, Costa Rica. Rev. Biol. Trop. 56 (Suppl. 2): 1-18.

Emig, C. C. 1971. Taxonomie et systématique des Phoronidiens. Bull. Mus. Natl. Hist. Nat. Paris, Zool. 8:469-568.

- 1979. British and other phoronids. Pages 1-57 in D. M. Kermack and R. S. K. Barnes, eds. Synopses of the British fauna, 13. Academic Press, London. 1982a. The biology of Phoronida. Adv. Mar. Biol. 19:1-89.

- 1982b. Nouvelles localizations de Phoronidens. Tethys 10:287-290.

- 2007. Phoronida of New Caledonia.
Page 173 in C. E. Payri and B. Richer de Forges, eds. Compedium of marine species of New Caledonia. Documents Scientifiques et Techniques II7.

1. 2009. Phoronids. Text pages 409411, Species list: Compact disc pages 383-384 in I. S. Wehrtmann and J. Cortés, eds. Marine biodiversity of Costa Rica, Central America. Springer Science + Business Media, Berlin.

Emig, C. C., and J. H. Bailey-Brock. 1987. Phylum Phoronida. Pages 171-181 in D. M. Devaney and L. G. Eldredge, eds. Reef and shore fauna of Hawaii, Sect. 2 \& 3: Platyhelminthes through Phoronida, and Sipuncula through Annelida. Bernice P. Bishop Mus. Spec. Publ. 64.

Emig, C. C., and A. N. Golikov. 1990. On phoronids of the Far Eastern seas of the USSR and their distribution in the Pacific Ocean. Zool. Zh. 69 (6): 22-30.

Emig, C. C., and C. Roldán. 1992. The occurrence in Australia of three species of Phoronida (Lophophorata) and their distribution in the Pacific area. Rec. S. Aust. Mus. (Adelaide) 26: 1-8.

Niermann, U., E. Bauerfeind, W. Hickel, and H. V. Westernhagen. 1990. The recovery of benthos following the impact of low oxygen content in the German Bight. Neth. J. Sea Res. 25:215-226.

Thomassin, B. A., and C. C. Emig. 1983. Distribution des Phoronidiens dans les biotopes littoraux, coralliens et terrigènes, du Canal de Mozambique (S. W. Océan Indien). Tethys 11:33-48.

Vargas, J. A. 1987. The benthic community of an intertidal mud flat in the Gulf of Nicoya, Costa Rica. Description of the community. Rev. Biol. Trop. 35:229316. 